\title{
The Investigation of Association between Transformational Leadership Behavior and Job Satisfactions Among Small Business in the United States
}

http://doi.org/10.21272/bel.5(3).6-21.2021

\author{
Abdulrahman Al-Ahmadi
}

$\mathrm{PhD}$, Science Researcher, Washington DC, USA

Karina Kasztelnik, ORCID: https://orcid.org/0000-0002-1090-3700

PhD, MBA, CPA, CTP, Accounting Professor, Colorado State University - Global Campus, Washington DC, USA

\begin{abstract}
This study has been the focus of much investigation in the search for the association between transformational leadership behavior and job satisfaction among small businesses in the United States. Several attempts have been made to the importance that small businesses have on the economy, and small businesses constitute over half of all jobs. No known empirical research has focused on exploring the association between transformational leadership behavior and job satisfaction among small businesses in Virginia. The research is based on a theoretical framework such as self-determination theory. The investigation of association qualitative research study was undertaken to explore the potential relationship between transformational leadership behavior and job satisfaction among small businesses in the United States. Results showed the importance improvement both personal lives and the health of small businesses and the microeconomy of the United States. Employee satisfaction has been a topic of interest for scientists for many years and has roots in multiple psychological theories that served as a basis for understanding job satisfaction. When employees trust leadership, this can contribute many benefits to the business, such as an increased focus on being productive at work, commitment to the organization, intent to stay with the organization, and increased profitability. Small businesses are also known for their innovation, job creation, and financial growth. Yet, some suffer from severe issues with inexperienced owner-managers, lack of resources, and competition that can significantly hinder their chances of success. The small businesses that struggle or are faced with closure represent an essential part of the economy that cannot be overlooked. However, despite their value in the economy, many still struggle due to multiple factors, including unskilled or incompetent leaders and owners, challenges related to technical expertise, and funding issues, including increased business costs that can be exacerbated by poorly performing owners or managers, who in turn may negatively affect employees as well. In fact, in developed countries, small businesses contribute $40 \%$ to $60 \%$ of the gross domestic product (GDP) and 67\% of employment. The research presented here confirms that the workplace is crucial in improving teamwork from the general perspective and approach. The findings can contribute to a better understanding of the transformational leadership style for all management levels and the effect on the job satisfaction of all employees hired by small business entities in the United States.
\end{abstract}

Keywords: Small Business, Transformational Leadership, Job Satisfaction, Organizational Strategies, Business Development.

JEL Classification: L21, J28, M00.

Cite as: Al-Ahmadi, A., Kasztelnik, K. (2021). The Investigation of Association between Transformational Leadership Behavior and Job Satisfactions Among Small Business in the United States. Business Ethics and Leadership, 5(3), 6-21. http://doi.org/10.21272/bel.5(3).6-21.2021.

Received: 11 July $2021 \quad$ Accepted: 28 August $2021 \quad$ Published: 13 September 2021

Copyright: (C) 2021 by the author. Licensee Sumy State University, Ukraine. This article is an open access article distributed under the terms and conditions of the Creative Commons Attribution (CC BY) license (https://creativecommons.org/licenses/by/ 4.0/).

\section{Introduction}

This research will add to the body of knowledge regarding how transformational leadership style can lead to improved employee satisfaction. Prior research has shown that transformational leadership style can increase employee satisfaction, but few have focused specifically on small businesses despite their significant 
contributions to the US economy (Dilger, 2019). This study will focus on examining this relationship in small businesses in Virginia.

Small businesses face challenges, including employee acquisition and retention (Morelix, 2018). Since transformational leadership style has been shown to improve employee satisfaction, there is value in assessing its usefulness in small businesses also. This study will quantify this relationship which can provide business leaders with tools for success. The questions that must be answered are what transformational leadership styles are observed in leaders of small businesses in Virginia and how satisfied their employees are. It is hypothesized that employees who are managed by transformational leaders will report higher job satisfaction. Selfdetermination theory (SDT) and transformational leadership are the theoretical frameworks for this research (Deci et al., 2017; Fernet et al., 2015; Ryan \& Deci, 2000). This is a correlational quantitative study between transformational leadership style as defined by Bass (1990), and employee satisfaction. Assumptions, scope, and delimitations are also covered. The limitations and challenges of this study included resources, time, and sample selection. The results of this study will be significant and valuable for business leaders and their team of employees.

\section{Background of the Study}

Several databases, including Business Source Complete, Business Source Elite, EBSCO Databases, MainFile, ProQuest, the Walden University databases, and Google Scholar will be utilized for this research exploration. Search terms included small business, transformational leadership, leadership styles, managers, management styles, employee satisfaction, and various combinations of these terms together. When searching for scholarly research, limiters were selected for scholarly papers only, and for this section, when there were sufficient results, the period searched was limited to the past five years. Morelix (2018) reported that small businesses are currently facing two challenges, namely employee retention and hiring new employees, with four out of ten small businesses having at least one unfilled opening, which is the highest percentage for this number in the past decade. Fulmer and Ostroff (Fulmer \& Ostroff, 2017), Para-González et al. (2018), and Yalabik et al. (2017) agreed that the research presents a clear relationship between job satisfaction, leadership style, and intention to quit, making it imperative to study whether the application of a transformational leadership style can lead to increased job satisfaction within the small business context.

Employee satisfaction has been a topic of interest for scientists for many years and has roots in multiple psychological theories that served as a basis for understanding job satisfaction. Early theories on what motivates human behavior include Maslow's (1943) hierarchy of five human needs which includes physiological, safety, love, esteem, and self-actualization. Later, Locke (1969) offered what has become the widely accepted view of job satisfaction which is described as the relationship between the needs and expectations of employees regarding their job and what can be achieved or attained from the job. More recently, Yalabik et al. (2017) outlined how job satisfaction encompasses multiple aspects of the work situation, including satisfaction with the work being performed, operating conditions, and the level of workload, among other things, and that it can also be described as a mental construct that is an emotional state regarding "what an employee perceives, feels and thinks about his/her job" (p. 249).

Research has shown that the levels of trust that employees have for top leaders and managers have hit an all-time low recently leading to the need for more research into how to increase trust between leadership and employees (Fulmer \& Ostroff, 2017). When employees trust leadership this can contribute many benefits to the business, such as an increased focus on being productive at work, commitment to the organization, intent to stay with the organization, and increased profitability. Ling et al. (2016) point out those leadership traits and attributes trickle down to frontline staff, which impacts the experience that customers enjoy with customer-facing employees. Martinaityte et al. (2019) posited that, when employees' needs are not satisfied, this failure leads to diminished motivation, as suggested by self-determination theory (SDT; Deci et al., 2017; Ryan \& Deci, 2000). The primary focus of their research were factors related to motivation including basic psychological needs as well as autonomous, or intrinsic motivation, which relies on internal motivators that result in employee engagement, while controlled motivation is coerced through rewards and punishment, both of which are discussed in more detail in the next section (Deci et al., 2017).

Fernet et al. (2015) explained that transformational leadership has been associated with other motivational outcomes among employees, including autonomous motivation, empowerment, and self-concordance. Choi et al. (Choi et al., 2016), explained that transformational leadership consists of several different elements, including individualized consideration, intellectual stimulation, inspiration, and visionary leadership. Aga et al. (2016), Cheng et al. (2016), and Choi et al. (Choi et al., 2016) cite multiple studies that have established a 
strong relationship between transformational leadership and job satisfaction. Many of the studies have been conducted in the nursing profession, limiting their usefulness to other industries. More research is also needed to gain a better understanding of how transformational leadership is related to project success, social identity, and teamwork (Aga et al., 2016; Cheng et al., 2016).

Early research on motivational factors that can explain behavior was studied and discussed by Deci (1971) who described autonomous motivators, which result from a genuine internal desire to perform a task, and controlled motivators, which include external forces such as money. Later research found positive correlations between teachers who favored autonomy and rewarded students with information led to the students being intrinsically motivated (Deci et al., 1981). It was Bass (1990) that first presented the idea of transformational leadership, which was based on the earlier concepts of what causes people to be motivated. Transformational leadership has continued to hold value in many fields and encompasses four aspects of leadership style which are idealized influence, inspirational motivation, intellectual stimulation, and individualized consideration (Kanat-Maymon et al., 2020). Cheng et al. (2016) applied the concepts of transformational leadership to the field of nursing, which is notoriously stressful and prone to burnout and turnover and found that nurses using a transformational approach to leadership created an organizational culture that led to high job satisfaction as well as increased quality of patient care.

Research into transformational leadership in small businesses has value for contributing to current knowledge in several ways. Small businesses differ from large businesses in terms of management, with small business owners acting as managers, or owner-managers, while large business owners will seek out managers rather than taking that role on themselves (Wang \& Poutziouris, 2010). Wang and Poutziouris also explain that owner-managers are highly involved in the daily functioning of small businesses, influencing, and controlling most of the business functions directly, making their leadership style a critical component to examine to increase our understanding of successful business management. In these ways, small businesses offer unique opportunities that are important for exploring the relationship between transformational leadership and employee satisfaction. Small businesses are also known for their innovation, job creation, and financial growth yet some suffer from serious issues with inexperienced owner-managers, lack of resources, and competition that can hinder their chances of success significantly. The small businesses that struggle or are faced with closure represent an important part of the economy that cannot be overlooked. Recent researchers reiterate the crucial role that small businesses play in terms of economic growth, creating jobs, social development, innovation, and creativity (H.S. $\mathrm{Ng}$ et al., 2016). According to $\mathrm{Ng}$ et al., small businesses are also vital in utilizing entrepreneurial skills garnered, such as transformational leadership, from small business ownermanagers to improve large business outcomes also.

Investment in small business leadership development has become a major ingredient for both developed and developing countries when creating policies. However, despite their value in the economy, many still struggle due to multiple factors including unskilled or incompetent leaders and owners, challenges related to technical expertise, and funding issues including increased business costs that can be exacerbated by poorly performing owners or managers, who in turn may negatively affect employees as well. In fact, in developed countries, small businesses contribute $40 \%$ to $60 \%$ of the gross domestic product (GDP) and $67 \%$ of employment. According to the US Small Business Administration Office of Advocacy (SBA; 2018), there are 30.2 million small businesses which constitute $99.9 \%$ of all businesses in the United States, and 58.9 million, or $47 \%$ of United States employees work at small businesses. The current study seeks to examine the relationship between transformational leadership and employee satisfaction to gain valuable information on how these challenges might be resolved. The results of this study will be significant and valuable for small business leaders in Virginia and their team of employees.

\section{Theoretical Foundation}

Self-Determination Theory (SDT). Self-determination theory is the primary theoretical foundation for this research (Deci et al., 2017; Fernet et al., 2015; Ryan \& Deci, 2000). The origin of SDT dates back to early research by Deci (1971) that explored how external rewards such as money and verbal reinforcement can influence intrinsic motivation when completing an activity. Motivational factors are the basis for SDT, of which there are various types, each with "functionally different catalyzers, concomitants, and consequences" (Deci et al., 2017: 20). SDT explains what causes people to behave the way they do. Understanding motivation is also quite helpful in the workplace. SDT has been successfully merged with The Full-Range Model of Leadership (FRML) and applied to distributive and procedural justice, with findings supporting that individuals who exhibit characteristics of transformational leadership instill a sense of trust in them by their subordinates (Kanat-Maymon et al., 2020). Research by Ismail et al. (2010) also found a positive relationship 
between transformational leadership and employee satisfaction using a self-developed, free-to-use transformational leadership study based on the well-known, but cost-prohibitive MLQ.

Self-determination theory (SDT) was first studied by Deci et al. (1989), who were tasked with helping a Fortune 500 Company that was facing challenges that were lowering profitability to make changes to their interpersonal conduct throughout the organization. In this project, three studies were administered, the Problems at Work study, the Work Climate Survey, and the Employee Attitude Survey. Many attributes that were of interest to SDT and measured by these studies are the same as those measured by the MSQ, including work atmosphere and working conditions, advancement, satisfaction with work in terms of personal autonomy, trust in and quality of their supervisor, compensation, feedback and recognition, security, and variety (Deci et al., 1989; Weiss et al., 1967). These commonalities between SDT and employee satisfaction help to explain how they are related to each other and this research.

Numerous studies have set out to study SDT and its role in motivating employees to complete work-related tasks. Deci et al. (2017) also posit that motivation for job activities can affect employee performance and wellbeing. SDT has been applied to many different industries including healthcare and education. Earlier theorists on human motivation agree that motivation plays a role in work performance, with intrinsic motivation as the primary focus (Deci \& Ryan, 1980a). This includes Piaget's cognitive development theory in 1952, Maslow's humanistic psychology in 1954, Atkinson's expectancy theory in 1964, and social motivation theories (Deci \& Ryan, 1980b). In 1981, Deci et al. explained that, according to cognitive evaluation theory, there are two types of motivation: (a) autonomous, which is often intrinsic motivation; or (b) controlling motivation. Their research also found that intrinsic motivation had a positive impact on behavior while controlling motivation had a negative impact. When individuals intrinsically motivated, they are engaged in an activity that they are performing willingly and by their own choice (Deci et al., 2017). These individuals are acting based on intrinsic motivation, that is, their motivation was a product of internal desires.

Controlled motivation, or extrinsic motivation, is characterized by using contingent rewards to motivate employees and has been shown to have negative consequences on overall employee job performance and work engagement (Deci et al., 2017). Contingent rewards differ from internally motivated rewards in fundamental ways. Self-interest is the foundation of contingent rewards (Barnett, 2017). Employees that are motivated by contingent rewards are performing job tasks to attain a reward of some sort. The contingent rewards are a product of an agreement between a leader and an employee where the leader offers a reward, the cost of the work, in exchange for successful completion of work tasks by employees. While contingent rewards do still motivate employees, the driving forces to do so are quite different. Leaders who use contingent rewards to motivate employees will often use punishment as a response to subpar performances. While this may aid in motivating employees to complete tasks, it does not necessarily create positive employee attitudes toward their work. In these ways, transactional motivation and contingent rewards differ significantly from transformational leaders that use rewards that are internal and more personally rewarding.

Fortunately, transactional leaders are also well versed in what the business needs and are willing to communicate these needs clearly and effectively so that employees have a solid understanding of their responsibilities within the company. Transactional leadership style still holds some value when trying to explain employee satisfaction, such as pay, and these factors must still be considered because they too affect employee satisfaction, but the focus is shifting toward transformational leadership due to its effectiveness in the workplace. Although transactional leadership will not be a primary focus of this research, it is an integral part of the FRML that is valuable for understanding the similarities and differences between it and transformational leadership, and the relationship that each has with employee satisfaction. Both leadership styles promote employee performance, but this research is more interested in the positive benefits of leading with a transformational style and how it may improve employee satisfaction and, in turn, help to achieve business goals as well.

Unlike intrinsic motivation, where employees are motivated more naturally, employees who are being motivated through extrinsic means are compelled by external demands that they are not in control of (Groen et al., 2017). Individuals who are motivated by extrinsic factors are accomplishing tasks to receive an external reward, such as a bonus. In addition, using extrinsic rewards to motivate employees may even reduce their autonomous motivation because they may feel inadequate for the job at hand, as indicated by the need for the reward. While monetary and other extrinsic rewards may act as motivation, their value has taken a secondary role in maintaining employee satisfaction. 
Transformational Leadership. Transformational leadership is another important part of the theoretical foundation for this research. Transformational leadership is certainly not a new concept, with it first being introduced by Burns in 1978 (Rudd et al., 2009). Burns' ideas helped to pave the way for leadership changes, including how people view and define leadership. Some experts consider transformational leadership to be the highest form of evolution in terms of leadership, and it has been the subject of many research projects with increasing interest in the second half of the 90s (Ghasabeh et al., 2015). As competition continues to fuel the economy, this trend in popularity will likely continue, especially considering the significant findings in research regarding transformational leadership style and employee satisfaction. The knowledge gained from this research will serve as the groundwork for small businesses in Virginia to succeed by implementing transformational leadership styles into everyday practices that may improve employee satisfaction and performance, and lead to positive business outcomes.

\section{Literature Review}

Small businesses are currently struggling with several challenging issues. The two major complaints, as reported by human resource professionals, are maintaining employee engagement and cultivating leaders in preparation for the future of the business (SHRM, 2017). This has left nearly half of small businesses with an open position that has not been filled (Morelix, 2018). Research has repeatedly shown that a relationship exists between transformational leadership style and job satisfaction and intention to quit, which shows the importance of understanding this regarding small businesses (Fulmer \& Ostroff, 2017; Para-González et al., 2018; Yalabik et al., 2017). The rationale for variable selection in this research is in part due to the challenges that businesses face today, with small businesses comprising a significant segment of the economy (Dilger, 2019). To remain relevant in a quickly changing world, business owners and managers need to approach employee satisfaction as a crucial part of the business. There is also an issue with a gap in the existing body of knowledge. Researchers have described a lack of research on the use of transformational leadership styles in small businesses (Wang \& Poutziouris, 2010). This problem is also evident when attempting to find any evidence of prior research on this through a scholarly search. Although several studies place priority on transformational leadership style within the context of large industries, the current study is interested in this relationship within the context of small businesses in Virginia. The results of this study could have serious implications for small business managers in Virginia that want to implement changes that improve employee satisfaction and job performance using a transformational leadership style.

Transformational vs. Transactional Leadership. Some of the earliest discussions of theories on leadership by Bass $(1990,1998)$, argue that there is no single style of leadership to use and that leaders can exhibit characteristics that are both transactional and transformational when leading employees (Barnett, 2017). While this may be true, the transformational leadership style has shown value over other styles of leadership. The transformational leadership style helps managers form positive relationships built on trust with their employees by showing empathy for them while being considerate and supportive (Jyoti \& Dev, 2015). This in turn creates intrinsic motivation for employees. Transactional leadership on the other hand involves an exchange of rewards or punishment in exchange for productivity and loyalty between the manager and employees, in an attempt to motivate them to perform specific tasks in a certain way (Saleem, 2015). Transactional leaders are less appealing and engaging for employees, often prioritizing personal agendas over that of others, and this style of leadership has even been shown to have a negative association with job satisfaction, often focusing on mistakes and amount of work achieved, or ignoring employees until a problem arises. It has also been found that transactional leaders are associated with more employees leaving the business than are transformational leaders. The transactional leadership style utilizes extrinsic forces, rewards, and punishment, to create motivation in employees. 


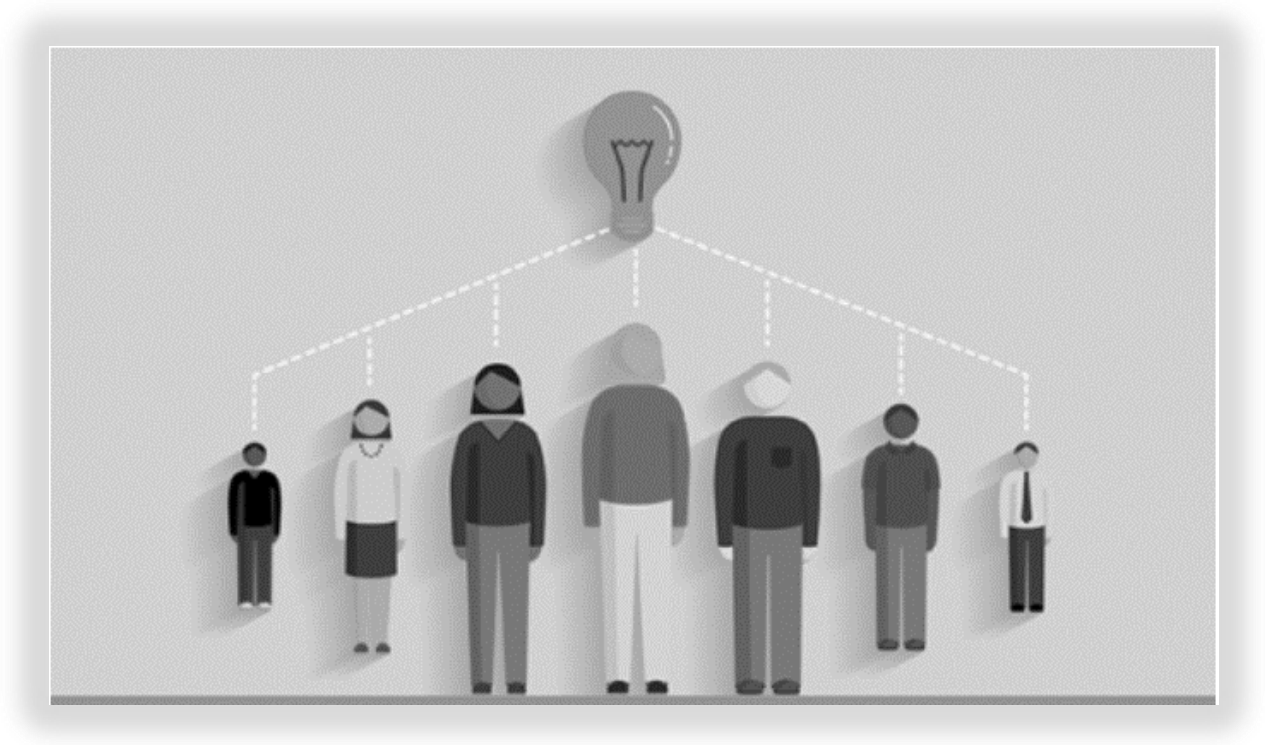

Figure 1. Transformational Leadership

Source: Steven ZoBell (August 15, 2019)

Transformational leadership, on the other hand, is a critical part of leadership style in business today. Even when compared with transactional leadership, the use of transformational leadership style has become a commonly used, effective method for successfully managing employees. Transformational leaders can foster trusting relationships with employees, which can lead to increased employee satisfaction and positive results for the company, whereas businesses that have transactional leaders have had challenges in terms of improvement (SHRM, 2017). While the value of transactional leadership cannot be disregarded, transformational leadership continues to surpass other leadership styles concerning employee satisfaction and performance. Transformational and transactional leadership styles are both relevant to the topic of employee satisfaction for different reasons. Traditionally, transactional leadership has been the method of motivating employees through external rewards and punishment that leads people to act. Transformational leadership is guided by the collective knowledge provided by earlier scientists who led the way to understand human behavior, formulated a framework for understanding the concept, and applied it to principles of business. Transformational and transactional leadership are part of the FRML.

The Full-Range Model of Leadership. Transformational leadership is part of a larger model of leadership. The Full-Range Model of Leadership, as developed and outlined by Bass and Avolio (1990), includes three constructs: (a) transformational leadership, (b) transactional leadership, (c) and laissez-faire leadership (Mathieu et al., 2014). Bass and Avolio (2000) also developed the Multifactor Leadership Study (MLQ) to assess leadership style using these three constructs. Transformational and transactional leadership have previously been treated as if they were a single entity when discussing theories of motivation, but each has different motivational factors. The third type of leadership in the Full-Range Model of Leadership is laissezfaire leadership. After researching this topic, it became apparent that perhaps it is the least effective method of leadership in this model. Leaders who exhibit laissez-faire leadership style take a very passive role as managers and are often taking a hands-off approach (Mathieu et al., 2014). These leaders are rarely present and will sometimes avoid taking any action to intervene. Laissez-faire leaders may also take their time when making decisions, may not give employees any feedback, and may also neglect to offer rewards for their job performance. This type of leader also fails to take actions that would help to increase employee motivation, often without recognizing the efforts of employees. The laissez-faire leadership style results in decreased employee job satisfaction and decreased satisfaction with the leadership. This style of leadership does not appear to be particularly helpful and may be detrimental to the success of a business.

Management-by-exception is another approach to leadership in the workplace. Management-by-exception is categorized along with the laissez-faire leadership style (Barnett, 2017). Management-by-exception is further subdivided into two parts: active management-by-exception and passive management-by-exception. Active management-by-exception is a type of leadership characterized by an involved leader. These leaders actively monitor employee performance, anticipating potential problems and intervening, when necessary, in the event of an actual issue. Management-by-exception requires leaders who are willing to take an active role in ensuring that employees are performing well. 
Passive management by exception does not take the same approach to problems. These leaders are reactive rather than proactive. They do not actively monitor employee performance and will only intervene when problems arise (Barnett, 2017). This type of leadership is often plagued by negativity, giving employees negative feedback, correcting them, criticizing their mistakes, and administering punishment. These leaders lack the qualities of transformational leadership that motivate employees using intrinsic rewards. Passive management by exception used to be considered a form of transactional leadership initially, but it was later recategorized as passive-avoidant, a dimension of laissez-faire. While all types of leadership roles may have the same overarching goals of task completion, each style varies significantly based on the behaviors exhibited by leaders and the response they get from employees in terms of performance and attitude towards work (Kasztelnik, 2020). This study will examine transformational leadership in depth. Transformational leadership is significant to the current study because it has been shown to promote higher levels of employee satisfaction and job performance (Mujkić et al., 2014). Recent research has also shown that employees who perceive their managers or leaders as transformational will demonstrate higher job satisfaction (Luturlean et al., 2019). As these results suggest, businesses that employ or train new transformational leaders would certainly benefit from having this type of leadership in their organization. There are four dimensions to the transformational leadership model: (a) idealized influence; (b) inspirational motivation; (c)intellectual stimulation; and (d) individualized consideration (Barnett, 2017). Each dimension of the transformational leadership model covers a different set of different yet related skills, characteristics, and features that are expected from transformational leaders.

Idealized Influence. The perception of leaders within an organization can influence the behavior of employees. Idealized influence refers to how leaders are perceived regarding features of charisma and confidence, consistency, consideration of other's needs first, and demonstration of high ethical standards and ideals (Barnett, 2017). These leaders can earn the trust of employees and create practical goals for them. The concept of idealized influence can be further broken down into two dimensions: (a) idealized influence behavioral (IIB); and (b) idealized influence attributed (IIA). IIA can be described as "how the leader is perceived by their followers," while IIB describes leader behavior (Barnett, 2017: 55). It should be noted that some theorists view idealized influence as a single construct, while others divide it into two separate dimensions as was done here.

Inspirational Motivation. Inspirational motivation is another important part of transformational leadership. Transformational leaders can inspire and motivate employees to perform at their best (Barnett, 2017). Transformational leaders use inspirational motivation to encourage enthusiasm and confidence in one's abilities (Barnett, 2017). Inspirational motivation also helps to promote dedication to the organization by example. Creating an open line of communication on expectations, which is in direct contrast with the laissezfaire leadership style, is a priority for transformational leaders. These leaders also take care to ensure that employees are involved in working toward achieving the company vision. This can help the employee to have a sense of ownership with their work when their efforts are aiding this goal. Leaders who can inspire their employees will see improvements in their satisfaction, dedication, and performance.

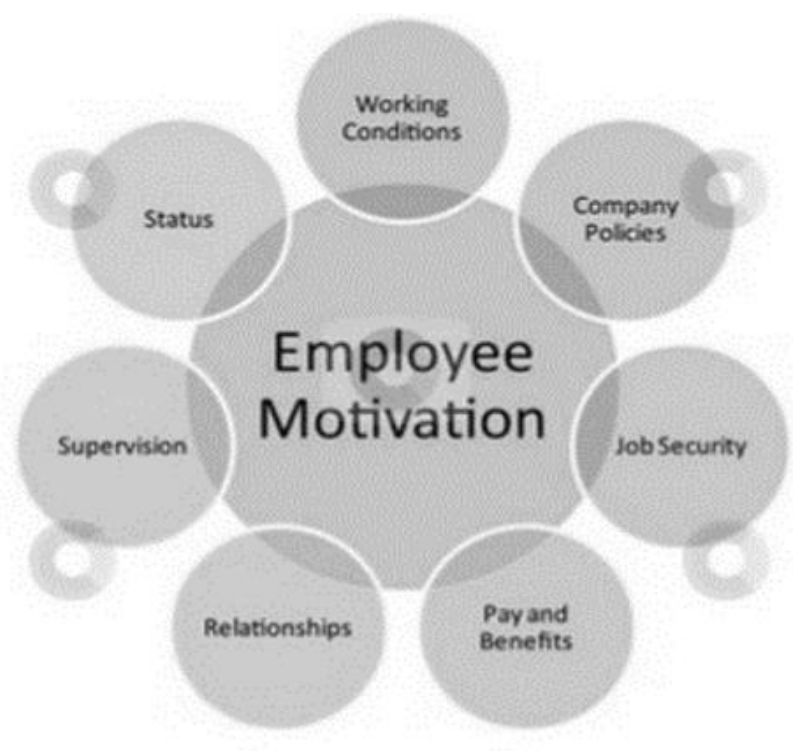

Figure 2. Employee Motivation 
Intellectual Stimulation. Intellectual stimulation is another important component of transformational leadership. Leaders that exhibit intellectual stimulation can help employees to be critical thinkers that can formulate ideas and find creative solutions to problems (Barnett, 2017). Leaders could accomplish this by giving employees problem-solving activities to complete and by avoiding negative responses to contributions that are of opposing opinions. By stimulating employees intellectually, they are likely to contribute new ideas to the company without fear of negative consequences and are instead rewarded for providing thoughtful suggestions (Kasztelnik, 2020).

Individualized Consideration. Leaders who exhibit individualized consideration for others in the workplace are appreciated and sought out for their guidance. The concept of individualized consideration refers to nurturing leaders who exhibit behaviors such as encouraging others and making others feel distinguished (Barnett, 2017). In doing so, these leaders often find themselves in roles such as advisors and teachers. Leaders who display individualized consideration will demonstrate activities that include "teaching, mentoring, reinforcement, active listening, and offering emotional and social benefaction to the follower" (Barnett, 2017: 55). These leaders aim to support their employees for the employees to reach their greatest potential. Activities such as these help the leader to attract followers in the workplace. Interestingly, these four dimensions of transformational leadership have different effects on leader performance, with idealized influence having the weakest influence on leader performance, and inspirational motivation having the strongest influence (Deinert et al., 2015). It would be valuable to examine inspirational motivation further to maximize its potential in business.

Transformational leadership plays a significant role in the business environment. Naeem and Khanzada (2017) found a significant and positive correlation between transformational leadership and job satisfaction. They also found a positive relationship between transformational leadership and project success. Research has also indicated that a positive relationship between job satisfaction and project success exists. These results are significant for businesses that are having problems with successful project completion. Bycio et al (1995) explain that their research found transformational leadership to be a factor that plays a significant role in affective commitment, which can reduce the chances of an employee leaving the company. It suggests that transformational leaders can potentially bring significant value to businesses through greater employee retention, which can reduce training costs, and less time lost on project involvement due to a revolving door of employees. Research also suggests that transformational leaders can pass their sense of moral obligation on to their employees. This essentially suggests that, by being morally obligated to an organization, leaders can invoke employees to respond to their work with a similar sense of moral obligation. It has also been determined that when employees feel a sense of ownership regarding their work, they will be more likely to perform and learn better (Deci et al., 2017).

These are important connections that cannot be ignored by businesses that want to succeed in remaining competitive. Each style of leadership has its strengths and weaknesses. Transformational leadership style differs from other styles due to its nature of making immediate economic and social changes to address internal problems while maintaining stability, appearance, and function that lead to the attainment of goals (Mujkić et al., 2014). Transformational leaders exhibit several traits that help them to create positive relationships with employees. For instance, research has shown that transformational leaders show empathy for their employees (Jyoti \& Dev, 2015). Transformational leaders are also considerate and supportive of their employees (Jyoti \& Dev, 2015). Transformational leaders can look beyond their personal needs and goals to consider the needs of their employees.

Transformational leadership has an impact on multiple facets of employee attitudes toward work. In addition to finding a relationship between transformational leadership and employee satisfaction, other research has found that some components of transformational leadership and employee job satisfaction can also improve employees' organizational commitment (Malik et al., 2017). Transformational leadership has also been shown to have a major positive impact on psychological empowerment and employee work attitudes (Lan \& Chong, 2015). Scientists have also found that transformational leadership can help leaders to foster an emotional connection with employees, which can help to increase organizational commitment (Top et al., 2014). Transformational leadership can also aid in employee creativity (Jyoti \& Dev, 2015). Transformational leadership has also been shown to have a positive impact on leader performance (Deinert et al., 2015). The laissez-faire leadership style, or management-by-exception, is a very hands-off approach that has little impact on intent to leave, while transformational leadership showed modest decreases in the intent to leave (Bycio et al., 1995). This shows how significant transformational leadership is for successful businesses and why the current research is also very important, as it will shed some light on this relationship in small businesses, specifically those in Virginia (Kasztelnik, 2020). 
The value of transformational leadership in the workplace has been shown repeatedly in previous research, across various industries and countries. The nursing field has been the subject of many studies on the positive outcomes of transformational leadership on employee satisfaction, but it has also been demonstrated in other fields such as education (Kouni et al., 2018). Transformational leadership can impact the school environment in positive ways, leading to desirable results for both job satisfaction as well as student performance and progress. The results of this study show that the transformational leadership style can be useful in different scenarios. Research has shown that numerous factors can contribute to employee satisfaction and performance. The top five determinants as indicated by $65 \%$ of employees in a study by the Society for Human Resource Management (SHRM, 2017) found that the most important contributor to job satisfaction was treating all employees, no matter their position within the company, with respect. Compensation and pay, as well as trust between employees and leaders, both closely followed with $61 \%$ of employees. Finally, $56 \%$ of employees reported that being able to use their skills and abilities when doing their job was very important. With two of these factors relating to transformational leadership, employee trust for managers, and the ability to utilize skills in the workplace, this lends support for the need for additional research in this area.

The FRML is useful for understanding the three leadership styles concerning each other. Transformational leadership has been emerging as an effective style of management over transactional leadership, which still motivates employees to perform work duties, but to a lesser extent. Laissez-faire leadership falls behind in effectiveness since these leaders often intervene only when necessary, such as when a problem arises. Transformational leadership is the focus of this research due to its increasing role in employee satisfaction and potential benefits to business entities. Another important theory of motivation is self-determination theory (SDT).

Self-Determination Theory (SDT). Self-determination Theory is a method of understanding and describing human motivation (Deci \& Ryan, 1980a). SDT is a macro theory that suggests that there are two types of motivations for behavior: (a) intrinsic and (b) extrinsic. Intrinsically motivated behaviors, also referred to as self-determined behaviors, involve making a conscious decision that fulfills a need. Extrinsically motivated, or automated, behaviors do not involve a conscious decision but instead are carried out without much thought or consideration. The primary difference between intrinsic and extrinsic factors as motivating behaviors is that the former is a self-determined behavior involving a conscious decision while the latter is not. Intrinsically motivated employees strive to do their best for internal reasons because they are personally invested in the work that they do. Employees who are motivated by extrinsic factors are still motivated to do their work but are not invested in the same way, completing tasks to gain an external reward. Without a reward, the task is essentially meaningless (Delanoy \& Kasztelnik, 2020).

In addition to healthcare and education, SDT has also been applied to various industries including sports, psychotherapy, parenting, and virtual reality (VR; Deci et al., 2017). SDT has also been shown to be successful in work motivation and management. It is for these reasons that SDT is the basis for this research. Prior research on SDT has shown that there are different types of motivation for job-related activities that affect employee performance and well-being. SDT places importance on the different types of motivation as well as each having different outcomes. It would be beneficial for managers to incorporate SDT into their management protocol to foster employee job satisfaction and performance. 


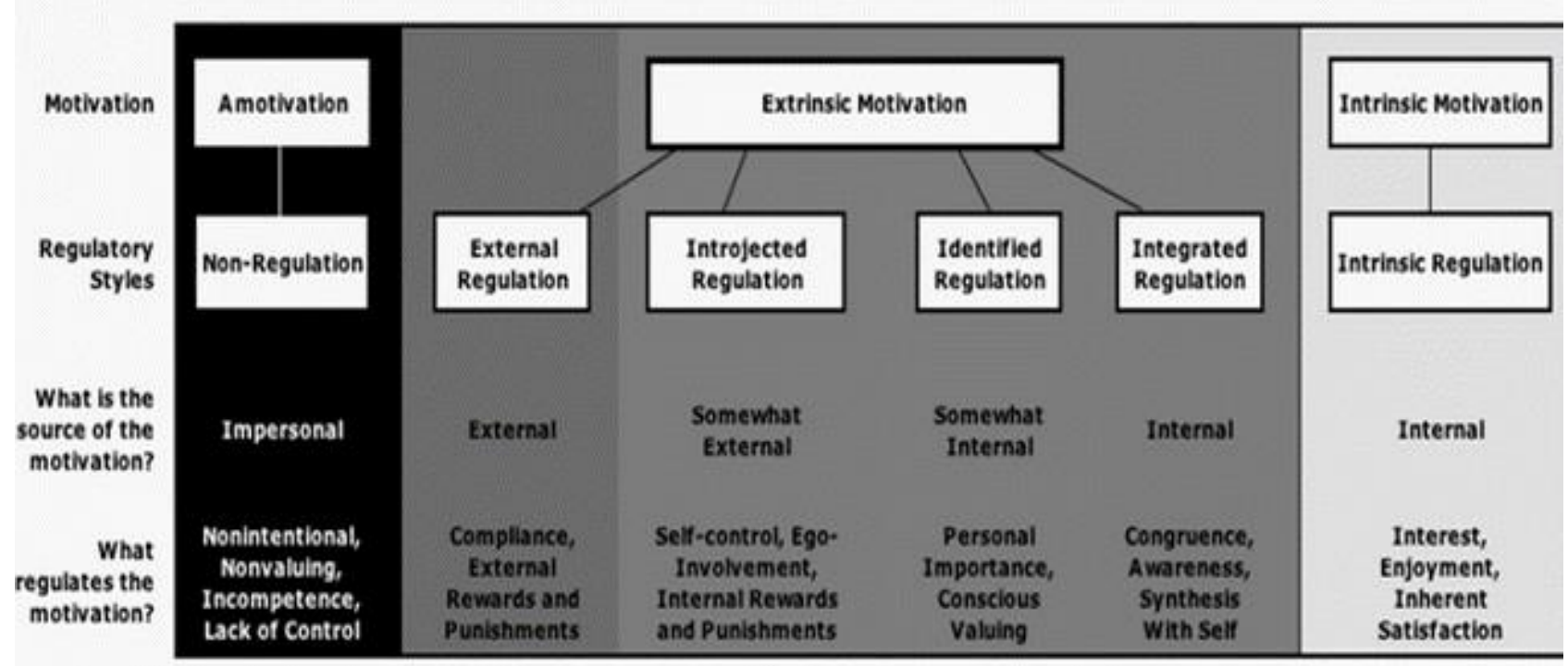

(Bused on Ayan, RM. B Deci, E.L. (2000). Seff-Determination Theory and the facilitation of Intrinsic Motivation, Social Development, and Wel-Being. Amencan Asychologist. SS(1), 65.78.)

Figure 3. The Self-Determination Continuum

Source: Positive Psychology

Self-determination theory (SDT) is based on the same basic concepts as FRML, with shared motivating factors including autonomous motivation (transformational leadership), controlled motivation (transactional leadership), and amotivation (laissez-faire leadership). This connected set of theories have been used together in research on perceptions of justice. Many prior studies have gotten similar results that show support for transformational leadership style and SDT leading to increased employee satisfaction.

Employee Job Satisfaction. Employee satisfaction is another important aspect of this research that must be considered, with a focus on transformational leadership in SDT and their role in maintaining employee satisfaction. Prior research shows that job satisfaction has a positive impact on the Loyalty of an employee (Onsardi et al., 2017). It shows how important it is for businesses to prioritize employee job satisfaction to retain employees for longer, potentially eliminating the extra costs associated with training and hiring new employees.

A significant amount of research has been conducted on employee job satisfaction. Early research about job satisfaction was discussed by Edwin A. Locke (1968) when he described human motivation. Locke explains that conscious ideas are the regulators of human actions. This theory aligns well with intrinsic motivation which suggests that behaviors are guided by well-thought-out and purposeful thoughts that lead to a conscious decision to perform a task. Locke explained that goals and intentions are moderated by the effects of incentives that are presented in exchange for the performance of the task. This has been repeatedly shown in research with similar findings regarding the type of rewards given playing a role in the level of employee performance. Similarly, Locke also found that monetary rewards, limitations on time, and knowledge of the results of their work did not play a role in performance without also being accompanied by goals and intentions that influence their behavior as well.

These results suggest the importance of internal motivation in influencing behavior. A few other points of interest were findings that concluded that employee job performance is improved in terms of output when the task is challenging, especially with particularly challenging tasks. These conclusions demonstrate the need for personally rewarding work that challenges them to perform at their best. The ideas surrounding job performance, job satisfaction, and what motivates individuals were covered in further detail in subsequent journal articles. Locke (1970) went on to explain that when an employee is satisfying a need to maintain their values, job performance, and job satisfaction increase according to the degree to which they are satisfying this need. Once again, a relationship between internal motivation, in this case, personal values about work, and outcomes of job performance on job satisfaction.

Prior research on transformational versus transactional leadership has shown that both types of leaders can influence employee behavior and therefore both have value, but transformational leadership has become the subject of numerous studies regarding its value in the workplace. Transformational and transactional leadership 
are both parts of the Full-Range Model of Leadership, along with laissez-faire leadership. This research is interested in learning more about the transformational leadership portion of the model which includes idealized influence, inspirational motivation, intellectual stimulation, and individualized consideration. SDT is another important theory that is closely tied to employee job satisfaction because both are interested in the factors that play a role in job performance. Transformational leadership has been repeatedly linked to employee satisfaction, but little is known about this relationship in small businesses. This study will help to advance knowledge on what transformational leadership skills are most closely related to employee satisfaction in small businesses so that new strategies can be developed that lead to more successful business management.

Personal values about work can include task-related values such as task activity and task success and achievement (Locke, 1970). Task activity refers to tasks that individuals find enjoyable simply due to being engaged in an interesting activity, without requiring proficiency, success, or extrinsic rewards to motivate them. These tasks are completed as self-serving actions. Task success and achievement, on the other hand, describes an individual's natural desire to become proficient in a task. This might include attaining a standard such as the quantity of output, the quality of output, rate of improvement, and project completion time. Another example would be finding a solution to a specific problem. Finally, reaching a measurable goal would be an example of task success and achievement, with success in reaching a goal being a pleasurable experience, whereas failing to succeed is considered an unpleasurable experience. While these statements may seem like obvious assumptions regarding motivation, these are the building blocks for numerous future studies on the topic.

Constructs of Interest. There are several constructs of interest in this research including employee performance and employee turnover rate. There are various scales for measuring employee performance, but this study will be measuring employee performance in terms of job time, quality, and quantity as defined by Na-Nan et al. (2018). Na-Nan et al. also designed a scale for measuring employee performance according to these terms. It is this employee performance scale that will be used in the current study.

Employee turnover rate is another constructive interest for this research. Although there is no single, agreedupon method for calculating the turnover rate, a commonly used equation is the number of employees leaving during a month divided by the number of employees, multiplied by 100 (Dessler, 2017). Sun and Wang (2016), refer to employee turnover simply as an employee leaving a business. They also explain that there are two types of turnover: (a) voluntary and (b) involuntary turnover. Voluntary turnover occurs when the employee decides to leave the company whereas involuntary turnover occurs when the employer chooses to remove, or terminate, their relationship with the employee. The study is more concerned with voluntary turnover and the reasons for employee departure from the business. Voluntary turnover can be further broken down into three categories: (a) push-to-leave, (b) pull-to-leave, and (c) pull-to-stay. Push-to-leave describes an employee's intent to leave, while pull-to-leave refers to the challenges, whether perceived or real, associated with acting on leaving, and pull-to-stay refers to factors that persuade employees to stay with the company. In addition to studying employee turnover, this study is also interested in turnover intention. For example, according to Sun and Wang the turnover intention would be measured using a statement such as "I would not want to work in any other office," which is then reverse coded. Employee performance and employee turnover rate are important to the current research since leadership style can affect these aspects and due to their overall potential impact on business. Since transformational leadership can be related to both constructs, they are also of interest to this research.

Mixed Findings. Despite many previous studies finding a positive relationship between transformational leadership style and employee satisfaction, a few have had different results. Some research found that transactional leadership, rather than transformational leadership, was rated as the highest perceived leadership style, with laissez-faire leadership trailing behind in third (Barnett, 2017). Their research also found that there were differences in how frequently respondents perceived each style of leadership, with all three appearing at a similar frequency, indicating that they were all used by leadership. These results are in contrast with most research that agrees that transformational leadership style has a positive influence on employee satisfaction. There are additional factors that must be considered when researching the relationship between transformational leadership and employee satisfaction. Some of these moderator variables include situational factors such as work environment, job requirements, time allotted for tasks, and organizational structure (Deinert et al., 2015).

What Remains to Be Studied. Many facets of transformational leadership remain to be studied. For instance, scientists could search for an explanation on the mixed findings of prior research on transformational leadership style and employee satisfaction to see why in many cases, transformational leadership style is 
preferred, but in a few, transactional leadership is preferred. There is also a need for more exploration of the various factors that can influence employee satisfaction. While a significant relationship has been found between transformational leadership style and employee satisfaction, there are several other components of employee satisfaction that can be studied in the future. These same aspects may have an interactive effect on transformational leadership research that must be considered. Caution must be taken when conducting research, to avoid confounds, and when interpreting results, to ensure that it is transformational leadership that is causing the change in employee satisfaction, versus other possibilities.

Another interesting finding of prior research is concerning specific personality traits that are associated with leader performance. Researchers found evidence to support connections between specific personality traits and leader performance. They explain that the Big Five personality traits, openness, conscientiousness, extraversion, agreeableness, and neuroticism, have an indirect effect on leader performance (Deinert et al., 2015). This effect occurred by way of all four dimensions of transformational leadership. While neuroticism negatively influenced leader performance, extraversion, openness to experience, and conscientiousness had a significantly positive effect on leader performance. Furthermore, by using a metaanalysis, they found that different combinations of personality traits had a positive effect on three of the four dimensions of transformational leadership, except for idealized influence. Future research on leadership would be wise to include a much closer look at the relationship between the Big Five personality traits and transformational leadership.

Deci et al. (2017) reviewed the current state of research regarding self-determination theory (SDT) rather than conducting an experimental research project. It contains valuable information about SDT from years of prior research on the subject by two of the authors, Deci \& Ryan. Their synopsis of the research includes a discussion on SDT in the workplace and defines the types of motivation that lead to actions such as autonomous motivation and controlled motivation. Also discussed are the three basic psychological needs which are competence, autonomy, and relatedness that play a role in creating greater motivation, performance, and wellness of employees. Research conducted by Ismail et al. (2010) was focused on transformational and transactional leadership and how those leadership styles affect procedural and distributive justice, as well as trust in leadership. Ismail et al. used the existing literature to create a conceptual framework and scale for their research. They also created the transformational leadership scale that will be used in this study also.

The research by Ismail et al. (2010) was beneficial for its contribution to theory by showing that implementing a transformational leadership style can increase the perceptions of followers in terms of procedural justice. When tested for validity and reliability, the transformational leadership scale surpassed the accepted standard, making it a trusted measurement tool. Their research also has value for leaders in other organizations that want to improve procedures for employee recruitment and management. Limitations of their research were like the current study since both used a cross-sectional design and both must consider the potential for response bias due to using self-report. The goal of the research conducted by Kanat-Maymon et al. (2020) was to contribute to the existing body of knowledge on leadership and what contributes to motivation through the merging of two theories, SDT and the Full Range Leadership Theory (FRLT) which have many overlapping concepts, into a single theory that is a framework for exploring work motivation and leadership.

The findings of research conducted by Kanat-Maymon et al. (2020) are important for establishing a link between supervisors' work motivation, which can influence their leadership style, and therefore, subordinates' motivation also. Their results may also aid in guiding future decisions by individuals who are responsible for the recruitment, training, and development of personnel. Weaknesses of their research include the inherent limitations of a cross-sectional design and the fact that their research focused more on the leader's perspectives than employees.

The article by Deci et al. (2017) was different from most of the sources because rather than conducting new research, they instead reviewed and summarized the existing body of knowledge on SDT. This was valuable for attaining a better understanding of the theory and how it relates to transformational leadership in many of the basic concepts that they share. Considering that Deci and Ryan are the original researchers at the forefront of SDT research. Extensive research was conducted by Ismail et al. (2010) on transformational leadership. Although their focus was on its relationship with the perception of justice, it also showed a positive relationship with trust, a factor that is important for employee satisfaction and performance as well. A cross-sectional design was used in their research as well as many others and served as a guide for the current study. Ismail et al. are also credited with the creation of the transformational leadership scale that will be used in this research due to its proven validity and reliability. Kanat-Maymon et al. (2020) also used a cross-sectional design for their research, in which they merge two theories of motivation, SDT and FRLT, to create a new framework for 
understanding transformational leadership style and its role in business processes. This prior research is invaluable for scientists moving forward who wish to study this relationship. It serves as a basis for education on the topic and provides useful tools for future researchers to conduct their research.

\section{Review and Findings}

To answer the research questions, a review and synthesis of prior research were crucial. There were two primary goals of the current research. The first was to determine what characteristics of transformational leadership are demonstrated by managers of Virginia small businesses. The second was to determine what the satisfaction level was as reported by employees of small businesses in Virginia who have a manager that demonstrates transformational skills. Two concepts serve as the theoretical foundation for the current research. These are self-determination theory, the fundamental concept which outlines human motivations, and transformational leadership, which describes the style of leading that has been shown to have a positive relationship with employee satisfaction (Deci et al., 2017). Transformational leadership style originated with Burns in 1978, when he first coined the term, while SDT was introduced in 1985 by Deci and Ryan (Deci et al., 2017; Rudd et al., 2009). By increasing knowledge on the function of SDT in connection with transformational leadership styles, business managers can create an atmosphere that leads to increased employee satisfaction and motivation in the workplace. As businesses face issues with employee engagement and creating future leaders, as reported by HR professionals, businesses must know how to overcome these challenges (SHRM, 2017). Despite the value of this knowledge in the business world, there is still a significant amount of research that could be done on this topic.

There are several reasons for assessing the relationship between transformational leadership style and employee satisfaction in small businesses. Researchers have found positive connections between transformational leadership style and creating trusting, considerate, and supportive relationships with employees (Saleem, 2015). While managers who exhibit transformational leadership create intrinsic motivation for employees through their behaviors and actions, transactional leadership relies on the exchange of rewards or punishment for productivity and loyalty. Both methods attempt to motivate employees but their methods for accomplishing this goal remain quite different. Gaining a better understanding of what motivates employees is key in creating an understanding, efficient, effective workplace environment.

Transformational leadership is a component of Avolio and Bass's Full-Range Model of leadership, which also includes transactional leadership and laissez-faire leadership (Mathieu et al., 2014). The transformational leadership style is a four-dimensional model that includes idealized influence, inspirational motivation, intellectual stimulation, and individualized consideration (Barnett, 2017). Transformational leaders exhibit numerous qualities in these areas that can positively impact employee satisfaction through inspiration, intellectual stimulation, and consideration of others. Transformational leaders are well suited for acting as advisors, teachers, and mentors because they are active listeners that offer emotional and social support. These leaders are advocates for their employees as they strive to improve, which can help to retain current employees and attract new employees. Transformational leaders have been shown to improve employee job satisfaction, project success, organizational commitment, and loyalty (Malik et al., 2017; Naeem \& Khanzada, 2017; Onsardi et al., 2017).

The benefits of using a transformational leadership style are not limited to a particular region or industry, but there have been repeated examples of transformational leadership creating positive results in the workplace (Kouni et al., 2018). SDT is another important theory related to employee satisfaction as it explains the motivators, which can be either intrinsic and extrinsic, lead an individual to complete a task (Deci \& Ryan, 1980a). The current study will explore transformational leadership and its role in employee satisfaction, with SDT as a basis for understanding human motivation. The literature review did reveal some contradictory results regarding which style of leadership was most frequently perceived in the workplace (Barnett, 2017). There is still plenty to learn about the different types of leaders there are and the role that each play in the workplace.

\section{Summary and Conclusions}

Employee job satisfaction has been studied for many years as scientists have looked for the answers on how to maximize business potential. Researchers have found strong evidence across various studies that support the idea that transformational leadership is a significant contributor to employee satisfaction. The review of existing literature showed that transformational leadership has a positive relationship with employee satisfaction and that it warrants additional research in the future to expand upon our knowledge of its influence. Although both play a role in motivating subordinates and are integral to the FRML, transformational and transactional leadership are very different in their mechanisms for enacting employees to complete work tasks. 
The FRML is the model of transformational and transactional leadership, as well as the laissez-faire leadership style. SDT is also relevant to the current study because it aligns with FRML very well, with the two complimenting each other so well that they have been combined into a single model in prior research. SDT and transformational leadership are both focused on internal and external motivating factors that play a role in employee job satisfaction. Both theoretical models also describe a third facet of the model that explains a type of leadership that distances themselves from their employees, essentially creating little to no motivation for employees, unless problems surface. Employee satisfaction is a crucial part of business management because it can have far-reaching consequences.

There is a growing need for research on transformational leadership and employee satisfaction. Businesses that employ or train leaders to display behaviors of transformational leadership that has been shown to improve employee satisfaction, invoking them to take actions that lead to positive outcomes. The importance of this relationship has been supported across numerous studies that show that businesses that are struggling might avoid decreased productivity and increased costs through transformational leadership. The significance of the relationship between transformational leadership style and employee satisfaction in business management has been repeatedly replicated in research over the years across many industries and regions of the world. Despite significant research on the topic, a lack of information on transformational style and its role in employee satisfaction in small businesses still exists. This study will help to fill the gap in research by evaluating the connection between transformational style and employee satisfaction in small businesses in Virginia. This will offer insight into whether the previously discovered relationship can be applied to the small business setting as well. In the future, researchers should explore this relationship in small businesses in states other than Virginia to see if the results are similar.

Author Contributions: Conceptualization: Abdulrahman Al-Ahmadi, Karina Kasztelnik; data curation: Abdulrahman Al-Ahmadi, Karina Kasztelnik; formal analysis: Abdulrahman Al-Ahmadi, Karina Kasztelnik; investigation: Abdulrahman Al-Ahmadi, Karina Kasztelnik; methodology: Abdulrahman Al-Ahmadi, Karina Kasztelnik; project administration: Abdulrahman Al-Ahmadi, Karina Kasztelnik; resources: Abdulrahman AlAhmadi, Karina Kasztelnik; software: Abdulrahman Al-Ahmadi, Karina Kasztelnik; supervision: Abdulrahman Al-Ahmadi, Karina Kasztelnik; validation: Abdulrahman Al-Ahmadi, Karina Kasztelnik; visualization: Abdulrahman Al-Ahmadi, Karina Kasztelnik; writing - original draft: Abdulrahman Al-Ahmadi, Karina Kasztelnik; writing - review \& editing: Abdulrahman Al-Ahmadi, Karina Kasztelnik.

Funding. There is no funding for this research.

\section{References}

1. Aga, D.A., Noorderhaven, N., \& Vallejo, B. (2016). Transformational leadership and project success: The mediating role of team-building. International Journal of Project Management, 34(5), 806-818. [Google Scholar] [CrossRef]

2. Barnett, D. (2017). Leadership and job satisfaction: Adjunct faculty at a for-profit university. International Journal of Psychology and Educational Studies, 4(3), 53-63. [Google Scholar] [CrossRef]

3. Bass, B.M. (1990). From transactional to transformational leadership: Learning to share the vision. Organizational Dynamics, 18(3), 19-31. [Google Scholar] [CrossRef]

4. Bycio, P., Hackett, R.D., \& Allen, J.S. (1995). Further assessments of Bass's conceptualization of transactional and transformational leadership. Journal of Applied Psychology, 80(4), 468-478. [Google Scholar] [CrossRef]

5. Cheng, C., Bartram, T., Karimi, L., \& Leggat, S. (2016). Transformational leadership and social identity as predictors of team climate, perceived quality of care, burnout and turnover intention among nurses. Personnel Review, 45(6), 1200-1216. [Google Scholar] [CrossRef]

6. Choi, S.L., Goh, C.F., Adam, M.B.H., \& Tan, O.K. (2016). Transformational leadership, empowerment, and job satisfaction: the mediating role of employee empowerment. Human Resources for Health, 14(1), 73. [Google Scholar] [CrossRef]

7. Deci, E.L. (1971). Effects of externally mediated rewards on intrinsic motivation. Journal of Personality and Social Psychology, 18(1), 105-115. [Google Scholar] [CrossRef]

8. Deci, E.L., Connell, J.P., \& Ryan, R.M. (1989). Self-determination in a work organization. Journal of Applied Psychology, 74(4), 580-590. [GoogleScholar] [CrossRef]

9. Deci, E.L., Nezlek, J., \& Sheinman, L. (1981). Characteristics of the rewarder and intrinsic motivation of the reward. Journal of Personality and Social Psychology, 40(1), 1-10. [Google Scholar] 
10.Deci, E.L., Olafsen, A.H., \& Ryan, R. (2017). Self-determination theory in work organizations: The state of a science. The Annual Review of Organizational Psychology and Organizational Behavior, 4, 19-43. [Google Scholar] [CrossRef]

11.Deci, E.L., \& Ryan, R.M. (1980a). Self-determination theory: When mind mediates behavior. The Journal of Mind and Behavior, 1(1), 33-43. [Google Scholar]

12.Deci, E.L., \& Ryan, R.M. (1980b). The empirical exploration of intrinsic motivational processes. Advances in Experimental Social Psychology, 13, 39-80. [Google Scholar] [CrossRef]

13.Deinert, A., Homan, A.C., Boerc, D., Voelpel, S.C., \& Gutermanna, D. (2015). Transformational leader ship sub-dimensions and their link to leaders' personality and performance. The Leadership Quarterly, 26(6), 1095-1120. [Google Scholar] [CrossRef]

14.Delanoy, N. \& Kasztelnik, K. (2020). Business Open Data Analytics to Support Innovation Leadership and Management Decision in Canada. Business Ethics and Leadership, 4(2), 56-74. [Google Scholar] [CrossRef]

15.Dessler, G. (2017). Human resource management. The Open University of Hong Kong. Available at: [Link]

16.Dilger, R.J. (2019). Small business administration and job creation. In Small Business and Jobs: Research and Analysis in Brief. Congressional Research Service. Available at: [Link]

17.Fernet, C., Trépanier, S.G., Austin, S., Gagné, M., \& Forest, J. (2015). Transformational leadership and optimal functioning at work: On the mediating role of employees' perceived job characteristics and motivation. Work Stress, 29(1), 11-31. [Google Scholar] [CrossRef]

18.Ghasabeh, M.S., Soosay, C., \& Reaiche, C. (2015). The emerging role of transformational leadership. The Journal of Developing Areas, 49(6), 459-467. [Google Scholar] [CrossRef]

19.Groen, B.A.C., Wouters, M.J.F., \& Wilderom, C.P.M. (2017). Employee participation, performance metrics, and job performance: A survey study based on self-determination theory. Management Accounting Research, 36, 51-66. [Google Scholar] [CrossRef]

20.Han, S.H., Seo, G., Yoon, S.W., \& Yoon, D. (2016). Transformational leadership and knowledge sharing. Journal of Workplace Learning, 28(3), 130-149. [GoogleScholar] [CrossRef]

21.Jyoti, J., \& Dev, M. (2015). The impact of transformational leadership on employee creativity: the role of learning orientation. Journal of Asia Business Studies, 9(1), 78-98. [Google Scholar] [CrossRef]

22.Kanat-Maymon, Y., Elimelech, M., \& Roth, G. (2020). Work motivations as antecedents and outcomes of leadership: integrating self-determination theory and the full range leadership theory. European Management Journal. [Google Scholar] [CrossRef]

23.Kasztelnik, K. (2020). Innovative Empirical Model for Predicting National Bank's Financial Failure with Artificial Intelligence Subset Data Analysis in the United States. Open Economics, 3, 98-111. [Google Scholar] [CrossRef]

24.Kasztelnik, K. (2020). Causal-Comparative Macroeconomic Behavioral Study: International Corporate Financial Transfer Pricing in the United States. Financial Markets, Institutions and Risks, 4(1), 60-75. [Google Scholar] [CrossRef]

25.Kasztelnik, K. \& Delany, N. (2020). Data Analytics and social media as the Innovative Business Decision Model with Natural Language Processing. Journal of Business and Accounting, 13(1), 136-153. [Google Scholar]

26.Lan, X.M., \& Chong, W.Y. (2015). The mediating role of psychological empowerment between transformational leadership and employee work attitudes. Procedia - Social and Behavioral Sciences, 172, 184-191. [Google Scholar] [CrossRef]

27.Ling, Q., Lin, M., \& Wu, X. (2016). The trickle-down effect of servant leadership on frontline employee service behaviors and performance: A multilevel study of Chinese hotels. Tourism Management, 52, 341-368. [Google Scholar] [CrossRef]

28.Locke, E.A. (1968). Toward a theory of task motivation and incentives. Organizational Behavior and Human Performance, 3(2), 157-189. [Google Scholar] [CrossRef]

29.Locke, E.A. (1969). What is job satisfaction? Organizational Behavior and Human Performance, 4(4), 309-339. [Google Scholar] [CrossRef]

30.Locke, E.A. (1970). Job satisfaction and job performance: A theoretical analysis. Organizational Behavior and Human Performance, 5(5), 484-500. [Google Scholar] [CrossRef]

31.Luturlean, B.S., Prasetio, A.P., \& Saragih, R. (2019). Increasing employee's job satisfaction through the implementation of transformational leadership and work stress level management. Journal of Management and Marketing Review, 4(3), 209-217. [Google Scholar] [CrossRef]

32.Martinaityte, I., Sacramento, C., \& Aryee, S. (2019). Delighting the customer: Creativity-oriented highperformance work systems, frontline employee creative performance, and customer satisfaction. Journal of Management, 45(2), 728-751. [Google Scholar] [CrossRef] 
33.Maslow, A.H. (1943). A theory of human motivation. Psychological Review, 50(4), 728-751. [Google Scholar] [CrossRef]

34.Morelix, A. (2018, December 20). The biggest reason the U.S. needs small businesses to thrive has nothing to do with taxes or the economy. Inc. Available at: [Link]

35.Mujkić, A., Šehić, D., Rahimić, Z., \& Jusić, J. (2014). Corporate psychopathy and the full-range leadership model. Economics, 259-270. Available at: [Link]

36.Na-Nan, K., Chaiprasit, K., \& Pukkeeree, P. (2018). Factor analysis-validated comprehensive employee job performance scale. International Journal of Quality \& Reliability Management, 35(10), 2436-2449. [Google Scholar] [CrossRef]

37.Ng, H.S., Kee, D.M.H., \& Ramayah, T. (2016). The role of transformational leadership, entrepreneurial competence and technical competence on enterprise success of owner-managed SMEs. Journal of General Management, 42(1), 23-43. [Google Scholar] [CrossRef]

38.Onsardi, A., Asmawi, M., \& Abdullah, T. (2017). The effect of compensation, empowerment, and job satisfaction on employee loyalty. International Journal of Scientific Research and Management (IJSRM), 5(12), 7590-7599. [CrossRef]

39.Para-González, L., Jiménez-Jiménez, D., \& Martínez-Lorente, A.R. (2018). Exploring the mediating effects between transformational leadership and organizational performance. Employee Relations, 40(2), 412-432. [Google Scholar] [CrossRef]

40.Rudd, H., Kent, T., Blair, C.A., \& Schuele, U. (2009). Leader behavior inventory: a test of measure equivalence in Germany and the United States. International Journal of Leadership Studies, 5(1), 22-36. [Google Scholar]

41.Ryan, R.M., \& Deci, E.L. (2000). Self-determination theory and the facilitation of intrinsic motivation, social development, and well-being. American Psychologist, 55(1), 68-78. [Google Scholar] [CrossRef]

42.Saleem, H. (2015). The impact of leadership styles on job satisfaction and mediating role of perceived organizational politics. Procedia - Social and Behavioral Sciences, 172(27), 563-569. [Google Scholar] [CrossRef]

43.The Society for Human Resource Management (SHRM) (2017). Employee job satisfaction and engagement: The doors of opportunity are open. Available at: [Link]

44.Top, M., Akdere, M., \& Tarcan, M. (2014). Examining transformational leadership, job satisfaction, organizational commitment and organizational trust in Turkish hospitals: Public servants versus private sector employees. The International Journal of Human Resource Management, 26(9), 1259-1282. [Google Scholar] [CrossRef]

45.United States Small Business Administration Office of Advocacy (SBA) (2018). United States small business profile. Available at: [Link]

46.University of Minnesota (2021). (MSQ) Minnesota Satisfaction Study. Available at: [Link]

47.Wang, Y., \& Poutziouris, P. (2010). Leadership styles, management systems, and growth: Empirical evidence from UK owner-managed SMEs. Journal of Enterprising Culture, 18(3), 331-354. [Google $\underline{\text { Scholar] [CrossRef] }}$ 